\title{
Giant liposarcoma of the back with 4 types of histopathology: a case
} report

\author{
Panoraia Paraskeva*1, Paraskevas Katsaronis ${ }^{1}$, Eleftherios D Spartalis ${ }^{1}$, \\ Andreas C Lazaris ${ }^{2}$, Hara Gakiopoulou ${ }^{2}$, Panagiotis Mallis ${ }^{3}$ and \\ Periklis Tomos ${ }^{1}$
}

\begin{abstract}
Address: ${ }^{2}$ nd Department of Propedeutic Surgery, National and Kapodistrian University of Athens, Medical School, 17 Agiou Thoma Str., 115 27, Athens, Greece, ${ }^{2} 1$ st Department of Pathology, National and Kapodistrian University of Athens, Medical School, 75 Mikras Asias Str., 115 27, Athens, Greece and "ENT Department, "Laiko" General Hospital of Athens, 17 Agiou Thoma Str., 115 27, Athens, Greece

Email: Panoraia Paraskeva* - noraparaskeva@hotmail.com; Paraskevas Katsaronis - pkatsaronis@yahoo.gr; Eleftherios D Spartalis - eleftherios.spartalis@hotmail.com; Andreas C Lazaris - alazaris@med.uoa.gr;

Hara Gakiopoulou - hgakiopoulou@med.uoa.gr; Panagiotis Mallis - greenpanos@gmail.com; Periklis Tomos - periklistomos@hotmail.com

* Corresponding author
\end{abstract}

Published: 16 December 2009

Cases Journal 2009, 2:9339 doi:10.1186/1757-1626-2-9339

This article is available from: http://www.casesjournal.com/content/2/1/9339

(c) 2009 Paraskeva et al; licensee BioMed Central Ltd.

This is an Open Access article distributed under the terms of the Creative Commons Attribution License (http://creativecommons.org/licenses/by/2.0), which permits unrestricted use, distribution, and reproduction in any medium, provided the original work is properly cited.
Received: 20 October 2009

Accepted: 16 December 2009

\begin{abstract}
The incidence of soft tissue tumours, both malignant and benign, is very common. However, the coexistence of 4 types of histopathology is rare and the aim of this article is to present one treated in our Department. An 87-year-old Greek man was treated in our Department for a huge tumour on his back, under local anaesthesia. The pathology report of the specimen referred 4 types of neoplasia. This case represents this incidence in a giant liposarcoma of the back.
\end{abstract}

\section{Introduction}

Soft tissue tumours are very common in the general population. Most of them are benign and they require excision for functional and appearance reasons. In literature the incidence of 4 types of histopathology in a specimen is very rare[1] and our aim is to present one.

\section{Case presentation}

An 87-year-old Greek man, who had been generally active and his past medical history was free of disease, was referred to our hospital for a giant swelling on his back. He has had this tumor since at least 10 years, but he had not undergone an operation as it has been asymptomatic (Fig. 1). Due to the dimensions of the tumor, the patient has undertaken a chest computer tomography scan in order to determine the borders and the invasion of the tumor to the surrounding tissues (Fig. 2)
The patient was referred for a surgical removal of the tumor. Due to his age, he has not taken general anesthesia and the whole operation has been under regional anesthesia. Intraoperatively, a giant liposarcoma, $18 \times 14 \times 6 \mathrm{~cm}$, was found and been removed and also another tumor, 12 $\times 10 \times 8 \mathrm{~cm}$, white and homogenous (Fig. 3, 4, 5).

The pathology report referred 4 types of neoplasia. There was growth of mesenchymal neoplasma with figure of non-differentiated liposarcoma. There was also growth of well-differentiated liposarcoma (Fig. 6), whereas in the non-differentiated parts of the tumor malignant fibrous histiocytoma (Fig. 7), osteosarcoma (Fig. 8), chondrosarcoma (Fig. 9) and parts with pericellular pattern were found. The skin segment was soft fibroma. 


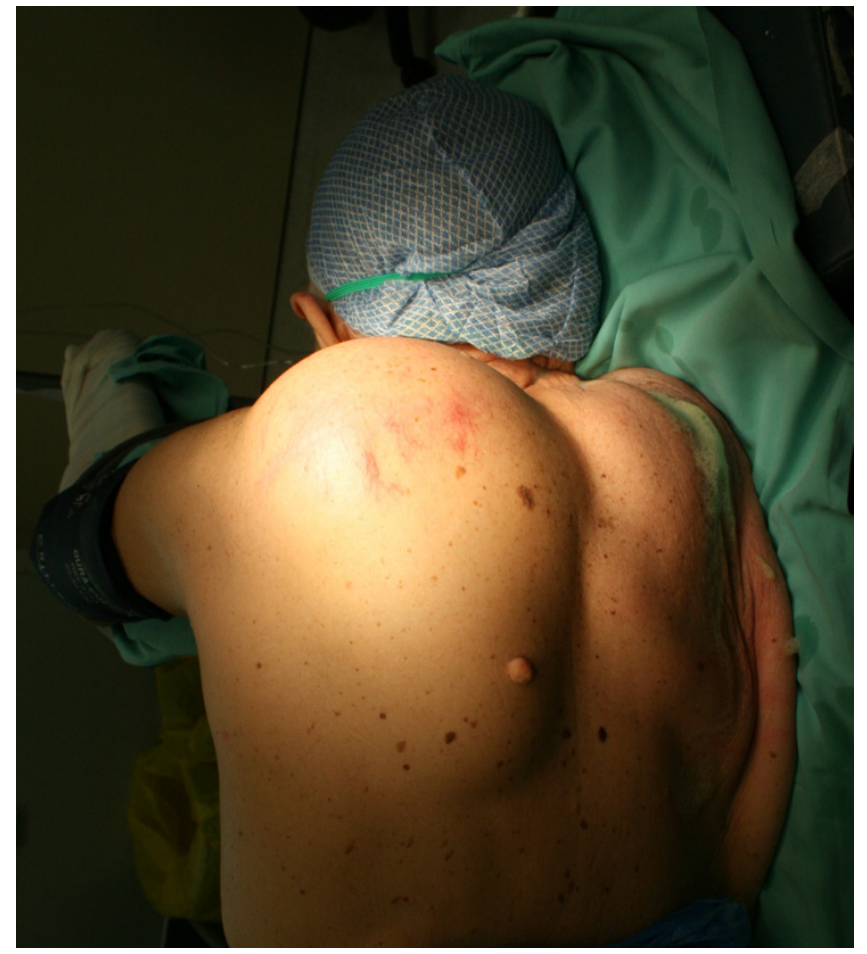

Figure I

Preoperative image of the patient

The perioperative period was uneventful and the patient was discharged home 3 days later.

\section{Discussion}

The existence of 4 histological types of neoplasia is very rare and was treated surgically under local anesthesia. Preoperative evaluation of such tumours is essential in order to determine the borders and characterize the tumour [2]. This can be done either with CT scan or MRI scan. The def-

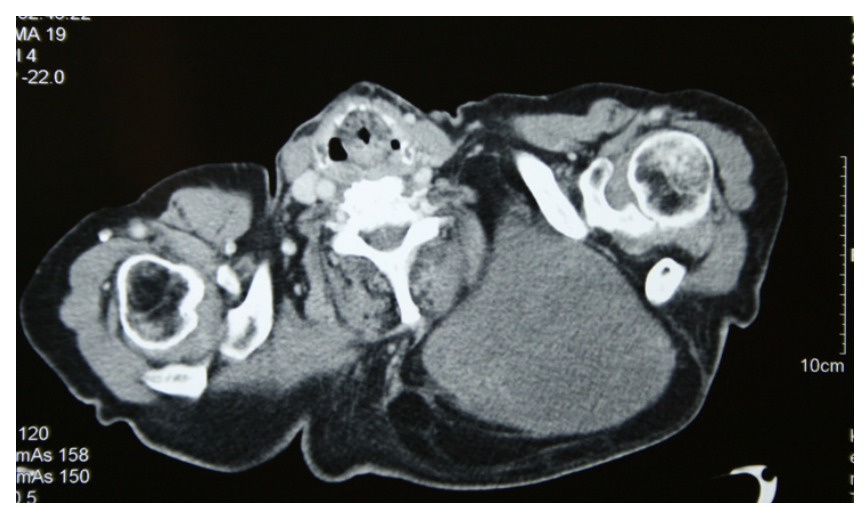

Figure 2

Chest CT scan of the patient

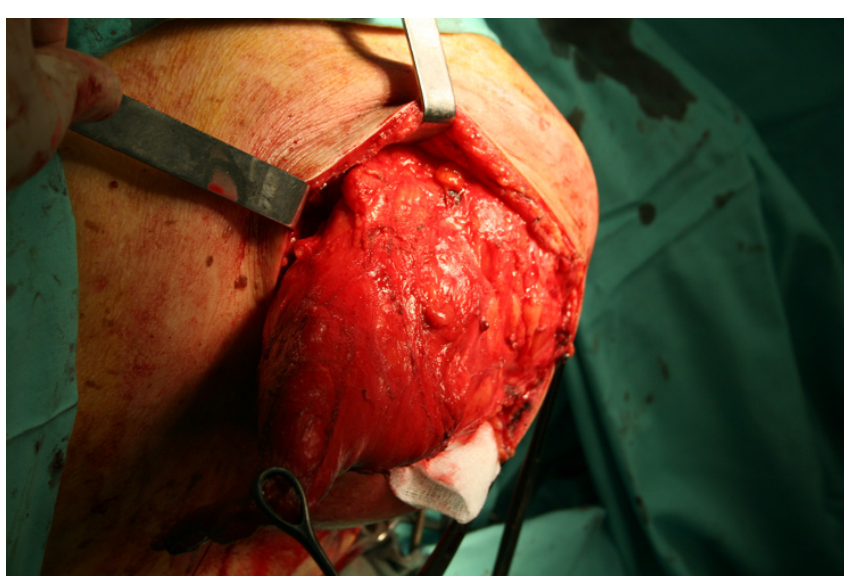

Figure 3

The tumor during the operation

inite diagnosis is set by histology and requires careful analysis of the specimen.

\section{Competing interests}

The authors declare that they have no competing interests.

\section{Authors' contributions}

PP analyzed and interpreted patient's files and wrote the paper. PK and ES contributed in the writing and also assisted at the operation. AL and HG performed the histological examination. PM assisted at the operation and looked after the patient postoperatively. TP was the responsible professor for the patient, decided and performed the operation.

All authors read and approved the final manuscript.

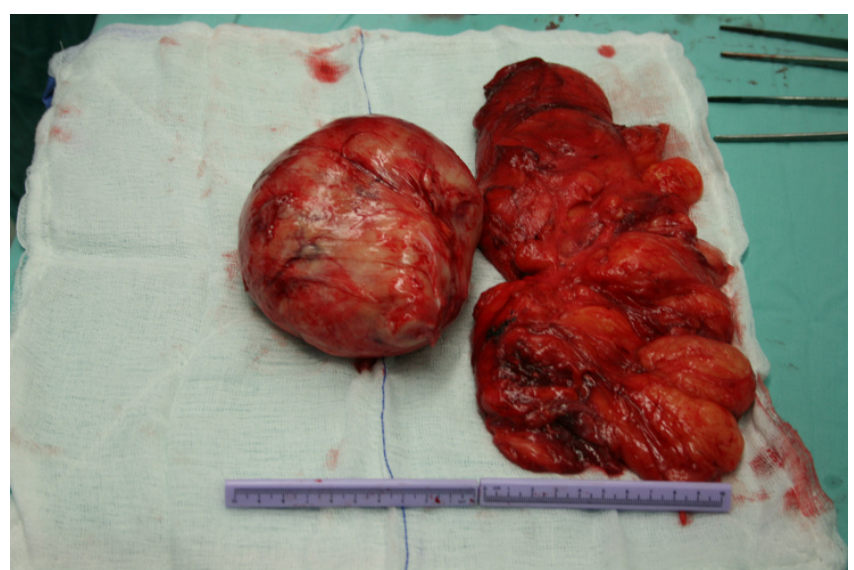

Figure 4

The actual size of the tumor 


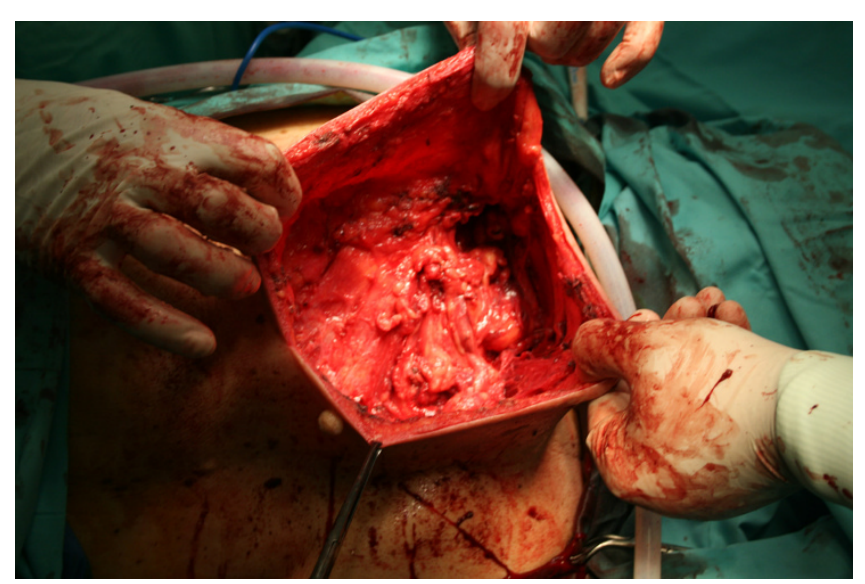

Figure 5

The area of the removed lesion

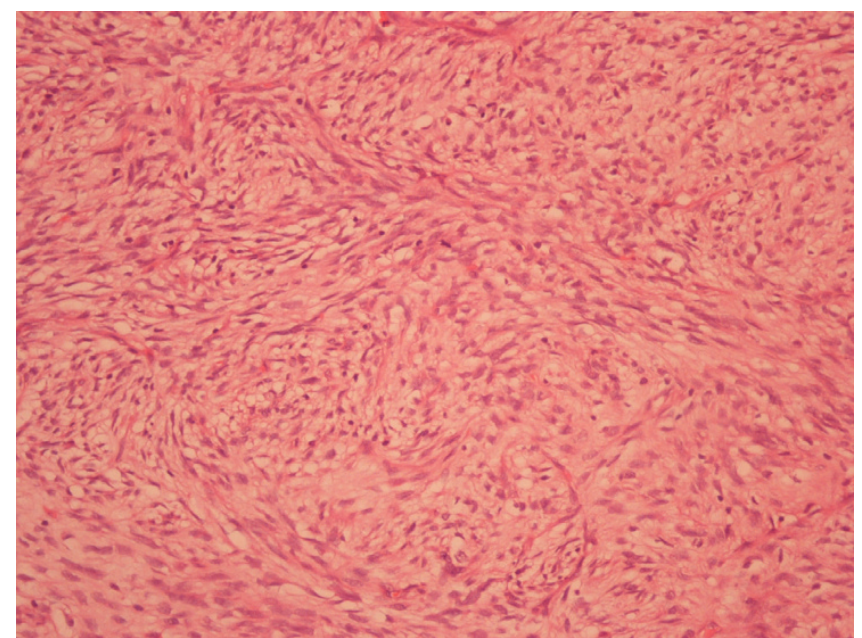

\section{Figure 6}

Growth of well differentiated liposarcoma (x 100) hematoxylin and eosin staining

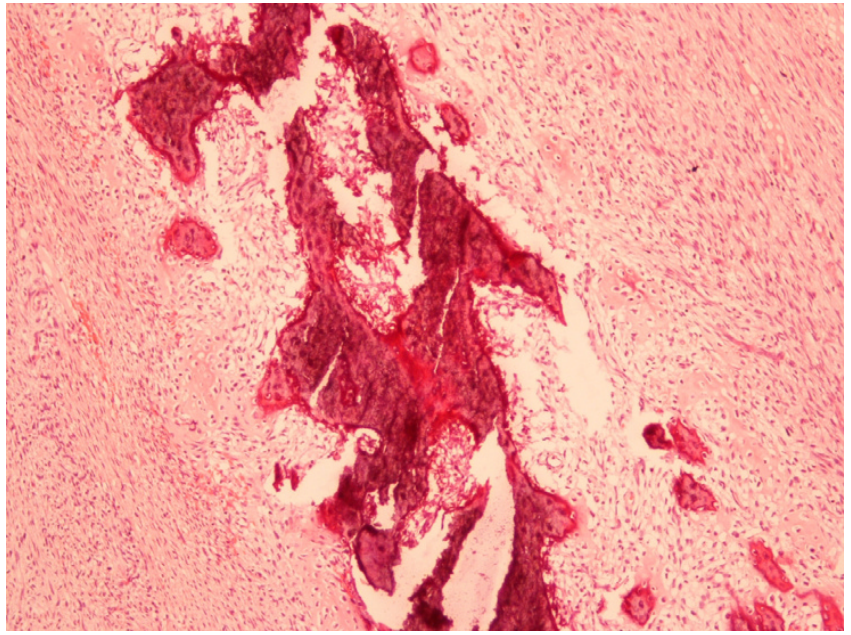

Figure 7

Non-differentiated part of the tumor with the pattern of malignant fibrous histiocytoma (x I00) hematoxylin and eosin staining

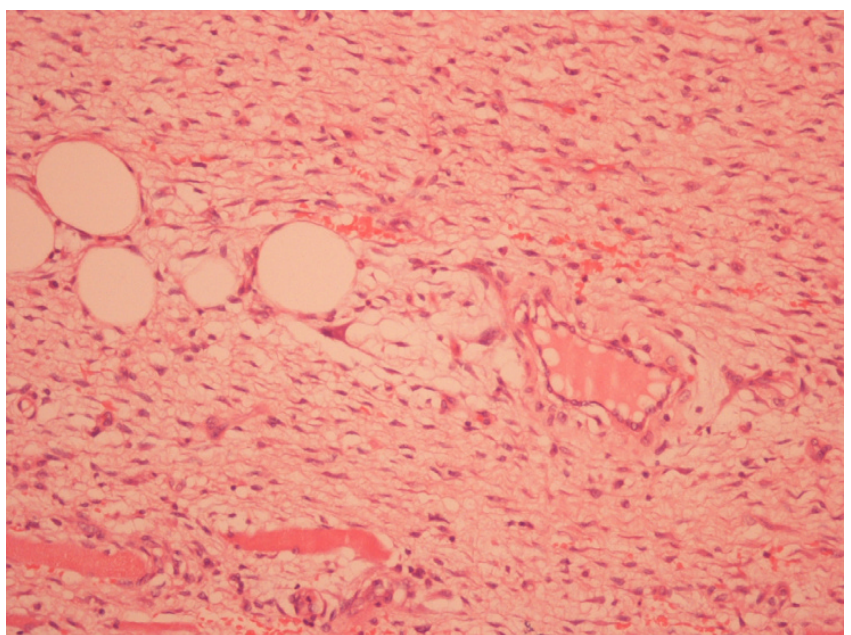

Figure 8

Part of osteosarcoma (X 200) hematoxylin and eosin staining 


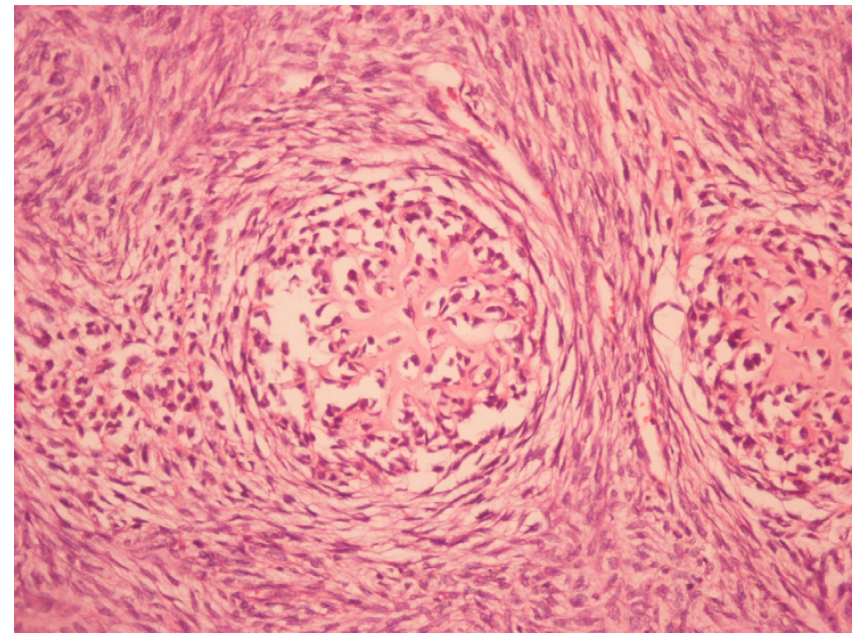

Figure 9

Part od chondrosarcoma (x 100) hematoxylin and eosin staining

\section{Consent}

Written informed consent was obtained from the patient for publication of this case report and accompanying images. A copy of the written consent is available for review by the Editor-in-Chief of this journal.

\section{References}

I. Shoji T, Sonobe M, Okubo K, Wada H, Bando T, Date H: Giant primary liposarcoma of the chest. Gen Thorac Cardiovasc Surg 2009, 57(3): $159-61$. Epub 2009 Mar 12

2. Lahat G, Madewell JE, Anaya DA, Qiao W, Tuvin D, Benjamin RS, Lev DC, Pollock RE: Computed tomography scan-driven selection of treatment for retroperitoneal liposarcoma histologic subtypes. Cancer 2009, I I 5(5): 108I-90.
Publish with Biomed Central and every scientist can read your work free of charge

"BioMed Central will be the most significant development for disseminating the results of biomedical research in our lifetime."

Sir Paul Nurse, Cancer Research UK

Your research papers will be:

- available free of charge to the entire biomedical community

- peer reviewed and published immediately upon acceptance

- cited in PubMed and archived on PubMed Central

- yours - you keep the copyright
BioMedcentral 